\title{
ONTOLOGÍA INDIRECTA E INDIVIDUACIÓN EN EL Último MERLEAU-PoNTY ${ }^{1}$
}

\author{
Indirect Ontology and Individuation in the later \\ Merleau-Ponty
}

Alessandro Ballabio ${ }^{2}$

Universidad Pedagógica Nacional

DOI: 10.17533/udea.rp.v10n1a04

Recibido: 2017-08-12 Aceptado: 2017-11-18

Para citar este artículo en APA: Ballabio, A. (2018). Ontología indirecta e individuación en el último Merleau-Ponty. Revista de Psicología Universidad de Antioquia, 10 (1), 93-116. DOI: 10.17533/udea.rp.v10n1a04

Resumen: Este artículo de reflexión muestra como la imposibilidad de conocer directamente el ser como presencia positiva abre el camino a la ontología indirecta, elaborada por Merleau-Ponty en Lo visible y lo invisible (2010). En esta obra, lo visible se entrecruza con su propia invisibilidad, y entre ellos hay una zona intermedia, que Merleau-Ponty llama carne, y que es una dimensión anónima y activa que permite la formación de los individuos. Para Merleau-Ponty y Simondon, la individuación se configura como un proceso vital, en el cual el encuentro con el otro no es un pretexto, sino la condición esencial para la formación de las identidades.

Palabras clave: visible, invisible, reversibilidad, carne, Simondon.
Abstract: This reflection paper shows how the impossibility of knowing Being directly as a positive presence, opens the way to Indirect Ontology, investigated by Merleau-Ponty in The visible and the Invisible (2010). In this work the visible is characterized by an invisible side. Between the visible and the invisible there is an intermediate zone, which Merleau-Ponty calls flesh, that is an anonymous and acting dimension that allows the formation of individuals. For Merleau-Ponty and Simondon individualization is a vital process, in which the encounter with the other is not a pretext, but the essential condition to form identities.

Keywords: visible, invisible, reversibility, flesh, Simondon.

1 Este artículo es resultado de investigación del proyecto Ética fenomenológica y formación (DED469-18), aprobado y financiado por el Centro de investigación de la Universidad Pedagógica Nacional (CIUP).

2 Doctor en filosofía de la Universidad Nacional de Colombia. Profesor titular ocasional e investigador de la Universidad Pedagógica Nacional de Bogotá. Correo electrónico: aballabio@pedagogica.edu.co; https://orcid.org/0000-0001-7922-8224. 


\section{Introducción}

En una de sus "Notas de trabajo de 1959", agregadas a Lo visible y lo invisible (2010), Maurice Merleau-Ponty afirma: "Los problemas planteados en $P h . P^{3}$ son insolubles porque yo allí parto de la distinción 'conciencia' 'objeto'” (p. 178). A partir de este pasaje, en el que el filósofo hace una autocrítica, constatar la problematicidad de esta relación (conciencia-objeto) abre el camino inédito de la ontología indirecta o nouvelle ontologie, que encuentra expresión, lamentablemente inacabada, en Lo visible y lo invisible. Se trata de una ontología que, por un lado, busca desvincularse del peligro de un pensamiento dualista anclado en la distinción conciencia-objeto; y, por el otro, intenta abrirse paso a la totalidad del ser, consciente de la imposibilidad de comprenderlo directamente. En otra nota de trabajo, de febrero de 1959, el filósofo francés escribe: "No se puede hacer ontología directa. Mi método 'indirecto' (el ser en los siendos) es únicamente conforme al ser" (Merleau-Ponty, 2010, p. 161). Por ende, en esta perspectiva, solo sería posible acceder al ser reconociéndolo indirectamente, a partir de los entes; evitando ponernos ante él como a una mera presencia, sino abordándolo, por así decirlo, lateralmente. De la misma forma, Gilbert Simondon, discípulo de Merleau-Ponty, afirma que una reforma de las nociones filosóficas fundamentales no puede anclarse en un concepto unívoco de ser, a saber, el ser en tanto es ${ }^{4}$, sino que debe considerar también el ser en cuanto ser en los en los entes o, en términos de Simondon, el ser en tanto individuado:

Es posible considerar la individuación como lo que, en el ser, debe ser conocido en primer lugar. Incluso antes de preguntarse cómo es legítimo o no alcanzar juicios sobre los seres, podemos considerar que el ser se dice en dos sentidos: en un primer sentido, fundamental, el ser es en tanto es; pero en un segundo sentido, siempre superpuesto al primero en la teoría lógica, el ser es el ser en tanto individuado (Simondon, 2009, p. 43).

3 Phénoménologie de la perception.

4 Al respecto, Germán Vargas Guillén (2015) afirma: "Simondon coincide con su maestro Merleau-Ponty en la ruptura con una 'ontología objetiva', con una concepción estructural del ser” (p. 56). 
En todo caso, cabe señalar que Lo visible y lo invisible (2010), si bien inaugura un nuevo modo de conocer el ser, no abandona la fenomenología husserliana, de la cual Merleau-Ponty es intérprete y continuador. Por el contrario, representa un intento de radicalización de su método, con el propósito de superar la distinción conciencia-objeto: "con Lo visible y lo invisible Merleau-Ponty emprende un camino filosófico verdaderamente inédito. Se trata, en efecto, de una superación de Husserl en su propio ámbito"5 (Seggiaro, 2009, p. 47). En esta perspectiva, el método fenomenológico nos propone introducir nuestra mirada, en el sentido de ser del mundo, interrogar su obviedad y ofrecer la razón de su darse. En otros términos, nos invita a escrutar el instante manantial del ser del mundo en su proceso de donación a una conciencia pura y a reflexionar sobre él. En este proceso de donación, el fenomenólogo es consciente tanto de que está siempre y originalmente implicado en el develarse del ser del mundo como de la imposibilidad de abarcar completamente su sentido. De hecho, según Merleau-Ponty, la enseñanza más grande que podemos obtener de la reflexión fenomenológica es su propia problematicidad e imposibilidad de realizarse completamente:

La mayor enseñanza de la reducción es la imposibilidad de una reducción completa. De ahí que Husserl se interrogue constantemente sobre la posibilidad de la reducción. Si fuésemos el espíritu absoluto, la reducción no sería problemática. Pero por estar en el mundo, porque incluso nuestras reflexiones se ubican en el flujo temporal que intentan captar (porque, como dice Husserl, sich einströmen), no hay ningún pensamiento que abarque todo nuestro pensamiento (Merleau-Ponty, 1993. pp. 13-14).

Esta imposibilidad estructural del pensamiento de abarcarse a sí mismo no debe entenderse como una condición provisional y defectuosa del método fenomenológico; por el contrario, se trata de una de las condiciones trascendentales de nuestro conocimiento. Afirmar que "no hay ningún pensamiento que abarque todo nuestro pensamiento" significa admitir la existencia de un hiato entre la consciencia y su objeto, que esencialmente no se puede colmar.

5 El autor de este artículo tradujo libremente al español las referencias de las versiones originales de los siguientes textos: Barbaras (1998); De Carlo (2012); De Saint Aubert (2005); Gambazzi (1999); Kirchmayr (2008); Lisciani-Petrini (1999); Merleau-Ponty (1959); Merleau-Ponty (1995); Prandoni (2000); Seggiaro (2009); Simondon (2005). 
Indudablemente, la fenomenología mantiene la distinción entre conciencia y objeto, y muestra su inseparabilidad en la estructura intencional; en este sentido, "Merleau-Ponty radicaliza este planteamiento y llega al nivel en que aquella distinción está efectivamente abandonada en favor de una indivisión originaria" (Seggiaro, 2009, p. 47). Sin embargo, no debemos interpretar esta indistinción originaria como un retorno a una concepción monista del ser, por la cual los opuestos se anulan mutuamente; más bien, se debe leer como el tentativo, por parte de Merleau-Ponty, de superar la distinción conciencia-objeto en favor de una visión más amplia del mundo sensible.

En este sentido, podemos empezar a entender de dónde nace la idea de concebir una nouvelle ontologie que desplace la atención de los polos de la relación conciencia-objeto a la divergencia estructural que esta misma polaridad implica. Dicho de otra forma, Merleau-Ponty quisiera incluir como tema peculiar de la investigación filosófica las dimensiones de distancia y de ausencia, que una consideración del ser en cuanto "ser pleno y positivo sobre fondo de nada” (Merleau-Ponty, 2010, p. 85) excluiría. Así, evitaría toparse con aquellas tendencias filosóficas que conciben el sentido de ser del mundo según el modelo de la simple presencia y que consideran la nada como algo ajeno a la manifestación: "Merleau-Ponty considera que precisamente el Ser, en su integridad en cuanto relación quiasmática de visible e invisible, se ha manifestado de manera originaria" (Prandoni, 2000, p. 456). Aquí está, en pocas palabras, el programa de la ontología indirecta merleaupontiana:

Nuestro punto de partida no será: el ser es, la nada no es — tampoco: sólo hay ser-, fórmula de un pensamiento totalizador, de un pensamiento de sobrevuelo, sino: hay ser, hay mundo, hay algo, en el sentido fuerte en que el griego habla de to $\lambda \varepsilon \gamma \varepsilon \iota v$, hay cohesión, hay sentido. No se hace surgir el ser a partir de la nada, $e x$ nihilo, se parte de un relieve ontológico y nunca puede decirse que el fondo no sea nada (Merleau-Ponty, 2010, p. 85).

\section{La no-visibilidad de lo visible}

Dadas estas premisas, se esboza una ontología que no descuida la nada en favor del ser, o lo invisible en favor de lo visible, sino que dirige su propia aten- 
ción sobre la "sensibilidad como dominio de la manifestación originaria del Ser, privando así de valor la separación metafísica entre sensible e inteligible" (Prandoni, 2000, p. 456). En esta perspectiva, resulta del todo inaceptable el proyecto de una ontología objetiva, según la cual "el trabajo del filósofo, que reflexiona sobre el Ser, consiste en hacer en una depuración del contacto inmediato que nosotros tenemos con el Ser, para discernir lo que es sólido, lo que resiste al intelecto" (Merleau-Ponty, 1995, pp. 169-170). En otras palabras, si se quiere seguir el camino de una ontología indirecta, debemos liberarnos de la tentación de objetivar el ser, reduciéndolo a una mera presencia, conscientes de que generalmente la experiencia sensible del ser visible estará en grado de revelarnos su carácter paradójico y ambiguo. En efecto, Merleau-Ponty está convencido de que el análisis del error filosófico, que consiste en creer que lo visible es una presencia objetiva o la idea de esta presencia, nos ayudará a entender la estructura de quiasma que entrecruza el ser y la nada, lo visible y lo invisible: "lo sensible, lo visible, debe ser para mí la ocasión de decir lo que es la nada - La nada no es nada más (ni nada menos) que lo invisible” (Merleau-Ponty, 2010, p. 227).

También para Simondon, el ser posee una estructura relacional y no objetiva, que el filósofo describe mediante la noción de unidad transductiva: "el ser no posee una unidad de identidad, que es la del estado estable en el cual ninguna transformación es posible; el ser posee una unidad transductiva; es decir que puede desfasarse en relación consigo mismo, desbordarse él mismo de un lado y otro de su centro" (Simondon, 2009, pp. 36-37). En este sentido, Vargas (2014) acota que el concepto de transducción "guarda relación con Merleau-Ponty en el concepto de quiasmo, modelo relacional, 'entre lo visible y lo invisible"' (p. 57). En efecto, tanto para Merleau-Ponty como para Simondon, la ontología es el estudio del ser en cuanto relación y despliegue de sí mismo, más allá de cualquier dualidad u oposición dialéctica entre el ser, como positividad, y la nada, como negatividad, entre lo visible y lo invisible. Según Simondon (2009), "el devenir es integrado al ser" (p. 184) y "lo que se toma por relación o dualidad de principios es de hecho despliegue del ser, que es más que unidad y más que identidad; el devenir es una dimensión del ser" (p. 37). 
Nuestra experiencia desafía la reducción que el pensamiento objetivo intenta aplicar al análisis del ser y de la nada y a la existencia como conciencia y como cosa. Con este análisis se querría que lo visible y lo sensible coincidieran, así como lo invisible y lo inteligible. De esta forma, lo invisible sería la mera negación de lo visible o un objeto accesible a otra visión, de tipo distinto con respecto a la dirigida a lo sensible mismo. Ciertamente, esta no es la concepción que Merleau-Ponty quiere afirmar en Lo visible y lo invisible (2010); al contrario, según Renaud Barbaras (1998), "lo invisible no es un objeto accesible a otra visión, sino una negación interna, un retirarse de lo visible: es la misma visibilidad de lo visible que implica una dimensión de invisibilidad" (p. 90). Y, en efecto, no hay otra cosa que lo visible; y lo inteligible, si bien es por definición la negación de lo visible, no se reduce a la negación de una presencia positiva. Así, como afirma de nuevo Barbaras, en Le tournant de l'expérience (1998): "lo invisible [...] testimonia una negatividad primera que no puede trascender verdaderamente lo sensible que permanece atrapado en él, en lugar de superarse hacia una nueva positividad" (p. 92). Debemos, entonces, entender la nada y la negatividad en cuanto horizontes de latencia internos al ser, y la invisibilidad como la fibra de lo visible o como la dimensión de ausencia o de retiro de lo visible, y no como una dimensión distinta de lo visible.

Esta introyección de la negatividad en el ser, de lo invisible en lo visible, nos empuja a abandonar los sistemas metafísicos tradicionales, que fijaban la nada en su negatividad pura, y la consideraban como algo puesto ante el ser.

Es demasiado decir de la nada que no es, que es negación pura: eso es fijarlo en su negatividad, es tratarla como una especie de esencia, es importar en ella la positividad de las palabras, cuando sólo puede valer como lo que no tiene nombre, ni reposo, ni naturaleza. Por principio, una filosofía de lo negativo no puede partir de la negación "pura", ni hacer de ella el agente de su propia negación (Merleau-Ponty, 2010, p. 85).

Si la nada debe ser considerada como la otra cara del ser, y lo invisible como una diferencia interna de lo visible, ya no podemos concebir lo invisible como una ausencia inerte incapaz de determinar el ser del mundo. Al contrario, lo invisible y la negatividad serían una ausencia que cuenta en el mundo o 
uno de los puntos de pasaje del sentido de ser del mundo. Y esto significa que ya no es posible pensar en el ser del mundo y en el ser tout court como en algo pleno, una presencia inmóvil sin sombras; sino que se necesita pensarlo a partir de su defecto de visibilidad, es decir, desde su invisibilidad como condición esencial de su hacerse visible. En este sentido, ni la nada pura ni lo invisible absoluto son el tema de la ontología indirecta merleaupontiana, sino lo invisible de este mundo, es decir, lo invisible como discrepancia, cavidad, laguna, déficit y, al límite, apertura de lo visible en su manifestarse. Lo invisible como invisible-de implica una

referencia a algo que, si bien está empíricamente ausente, ya entra en la constitución de las cosas presentes, razón por la cual ver equivale a mantener en la sombra. La visión se da si hay cavidad, si permanece abierto el lugar de la casi-visión, si queda un excedente (De Carlo, 2012, p. 57).

Del mismo modo, vale la pena subrayar que renunciar a la idea de la nada y de un ser absoluto no implica necesariamente creer en un ser meramente representado o imaginado. La nada no es un vacío de ser, así como lo invisible no representa una ruptura irreparable en el tejido de lo visible, sino que es su pliegue o su cavidad. De aquí deriva la imposibilidad de construir una filosofía o una ontología directa del ser y de la nada, dado que lo que no existe se configura como algo que aún no es: es un ser de latencia que se debe observar lateralmente o, por así decirlo, de reojo. De la misma forma, no debemos representarnos o imaginarnos el pasado o el futuro como no-seres vacíos o como huecos en el entramado del presente que deberíamos completar con nuestra imaginación. Por el contrario, es necesario mirarlos a través de las lagunas y los pliegues del presente, como momentos aún no presentes.

La continuidad esencial entre el ser y el no ser que la ontología indirecta de Merleau-Ponty propone se podría malinterpretar como un regreso a lo inmediato o a una fusión originaria entre los dos polos de la relación. En cambio, es oportuno reafirmar que la continuidad entre el ser y el no ser no se obtiene en detrimento de la identidad de los opuestos. Lo visible "debe excederse a sí mismo, hasta implicar lo invisible, sin cesar de ser el mismo, lo cual significa que debe implicar en sí mismo su propia negación: lo que lo sobrepasa, es de- 
cir, lo invisible, el aún lo contiene" (Barbaras, 1998, p. 89). En general, en Lo visible y lo invisible (2010) domina un sentido de ser "del cual todo lo que se puede decir es que es algo en la medida en que no es nada" (Barbaras, 1998, p. 52). Entre ser y nada y visible e invisible hay continuidad y, al mismo tiempo, discontinuidad: lo invisible se presenta como una diferencia interna a los pliegues de lo visible. La coincidencia se ha perdido, lo visible es casi-visible y su darse es en realidad un retraerse que exhibe estructuralmente una dimensión de escondimiento, es decir, una zona de sombra que es el tema central de la nouvelle ontologie merleaupontiana. Es más, es justo en virtud de esta no coincidencia y distancia crítica entre visible e invisible que algo se ofrece a nuestra experiencia. De hecho, lo que hay no es una coincidencia de principio o de presunción y una discrepancia de hecho, una verdad mala o fallada, sino una división privativa, una coincidencia de lejos, una distancia, y algo así como un "buen error" (Merleau-Ponty, 2010, p. 115). Un buen error, una carencia de ser que nos permite ver las cosas en su darse individual en carne y hueso.

\section{La donación en carne}

La divergencia estructural entre visible e invisible se configura, entonces, como la condición capaz de ofrecernos el objeto de conocimiento, asi como es, en carne y hueso. Es decir, no se nos presenta un objeto absoluto y sin fondo, sino siempre en perspectiva y, por lo tanto, caracterizado por zonas de sombra y por un modo de manifestarse que no excluye una cierta ambigüedad. La donación en carne del objeto, es decir, en perspectiva, no debe entenderse como una condición obstaculizadora que deberíamos superar o evitar para lograr una visión sin ambigüedades. Por el contrario, justamente la ambigüedad de la donación en carne del objeto sensible resulta ser el rasgo característico de su ser. En otros términos, la donación en carne se caracteriza por un buen error o una ambigüedad buena, que nos permite detectar el ser en cuanto sensible y que no se debe entender como contradicción. En particular, nuestra percepción del darse en carne del mundo siempre se caracteriza por una impercepción o por un punctum caecum, que representa una dimensión 
de apertura al mundo, en el mundo, y que funciona como referencia para cualquier otra experiencia.

Según Barbaras (1998), Merleau-Ponty retoma la perspectiva husserliana, para la cual la percepción es definida en primer lugar como donación en carne y hueso y no como sensación. Ciertamente, el filósofo francés subscribiría la afirmación según la cual la donación en carne es donación óptima, también en el caso en que el objeto no sea directamente percibido como presente. Al mismo tiempo, radicaliza esta misma posición y nos invita a no concebir la donación en carne en cuanto fenómeno meramente positivo, con el riesgo de malinterpretarla con la noción husserliana de compleción intuitiva. En efecto, "la presencia carnal, lejos de ser sinónimo de intuición, es el fondo a partir del cual cualquier cosa como un objeto puede dotarse de un sentido" (Barbaras, 1998, p. 85). Definir la percepción del objeto como intuición significa reconocer la presencia plena y exhaustiva de algo como única modalidad posible de su mismo darse; y, correlativamente, caracterizar la experiencia como saturación de la mirada vacía que se dirige a un objeto pleno. En otras palabras, definir la percepción como intuición es "rechazar la posibilidad de una diferencia o de una distancia que sean constitutivas" (Barbaras, 1998, p. 245). Si la percepción se piensa exclusivamente como compleción intuitiva de una tendencia vacía, es decir, "en términos de obturación de este vacío, es decir, como presencia positiva, de intuición” (Barbaras, 1998, p. 245) que colma nuestra espera, se plantea el problema de cómo concebir la dimensión de ausencia que pertenece estructuralmente a lo que se da en carne y hueso. En efecto, si la donación del objeto llenara completamente nuestro campo visual, ¿cómo deberíamos entender el residuo de invisibilidad que lo visible implica esencialmente? Sin embargo, es oportuno recordar que "la carne no se caracteriza como modo de donación; ella es más bien la presencia originaria sobre cuyo fondo se puede pensar cualquier donación” (Barbaras, 1998, p. 85).

Ahora, si la donación en carne se configura como el fondo de cada posible experiencia del mundo, no podríamos considerarnos ajenos a ella. En cambio, en cuanto sujetos videntes, estamos envueltos en la situación del mundo y somos homogéneos con ella. Así, la donación en carne resulta ser aquel marco de significado de todos nuestros actos y el fondo latente que brinda consistencia 
a nuestra experiencia. En términos husserlianos, sería, entonces, la intencionalidad operante (fungierende Intentionalität) interior al ser, y no la unidad de la conciencia, lo que garantiza la unidad de nuestros actos. En todo caso, Merleau-Ponty encuentra en el análisis de Husserl los mismos límites que atribuía a sí mismo con referencia a la Fenomenología de la percepción:

Todo el análisis husserliano está bloqueado por el marco de los actos que le opone a la $\varphi$ [filosofía] de la conciencia. Hay que retomar y desarrollar la intencionalidad fungierende o latente que es la intencionalidad interior al ser. [...] Hay que tomar como principal, no la conciencia y su Ablaufsphänomen con sus hilos intencionales diferentes, sino el torbellino que ese Ablaufsphänomen esquematiza, el torbellino espacializador-temporalizador (que es carne y no conciencia ante un noema) (Merleau-Ponty, 2010, p. 216).

Lo que se debe asumir primeramente como tema central de la investigación de la nouvelle ontologie no es, entonces, la conciencia frente a un noema, sino el torbellino espacializador-temporalizador que es la donación en carne. En cuanto sujetos de la visión y a la visión, quedamos atrapados y envueltos en el torbellino espacializador-temporalizador de la carne, sin poder mirar el mundo desde otro lugar, sino exclusivamente desde el corazón de lo visible mismo. No somos sujetos de sobrevuelo, kosmotheoros que escrutan el mundo desde lo alto o de frente, y que fijan las cosas cada una en su tiempo y en su lugar, como si fuéramos individuos absolutos ubicados en una sede única y determinada. Merleau-Ponty se pregunta provocadoramente:

Pero ¿̇soy yo kosmotheoros? Más exactamente, ¿lo soy a título último? ¿Soy primitivamente poder de contemplar, pura mirada que fija las cosas en su lugar temporal y local, y las esencias en un cielo invisible, ese rayo del saber que debería surgir de ninguna parte? (Merleau-Ponty, 2010, p. 105).

¿Desde dónde, entonces, miramos el mundo? Y al mismo tiempo, ¿desde dónde somos mirados? ¿Desde el fondo de la nada? Por el contrario:

Lo visible no puede llenarme y ocuparme, porque yo, que lo veo, no lo veo desde el fondo de la nada sino desde el medio de él mismo, yo, el vidente, también soy visible. Lo que hace el peso, la consistencia, la carne de cada color, de cada sonido, de cada textura táctil, del presente y del mundo, es que quien los aprehende se 
siente emerger de ellos por una especie de enroscamiento o de repetición, fundamentalmente homogéneo a ellos (Merleau-Ponty, 2010, p. 106).

Si lo visible se entiende como algo que envuelve nuestra subjetividad, entonces, cesa de ser inaccesible y la visión de las cosas depende a su vez de los límites de la topología en la cual estamos inscritos. Ya no es posible una visión global o de sobrevuelo para el sujeto encarnado en el mundo y abierto al mundo, "sino que depende del punto de vista particular y finito en el ser, por lo cual se accede a la verdad solamente a través de perspectivas, escorzos y aproximaciones. Tal punto de vista niega cualquier sobrevuelo metafísico" (Kirchmayr, 2008, p. 212). En otras palabras, lo visible aparece siempre sobre un fondo de no visibilidad, que nunca deja de tener profundidad. Es más, precisamente la profundidad resulta ser la condición esencial del darse de las cosas:

Es ella entonces la que hace que las cosas tengan una carne: es decir, oponen a mi inspección obstáculos, una resistencia que es precisamente su realidad, su 'apertura', su totum simul. La mirada no vence a la profundidad, la cambia (Merleau-Ponty, 2010, p. 194).

No evita los obstáculos que se interponen entre ella y las cosas, sino que, en virtud de la profundidad, cerca y rodea las cosas y deja que ellas la revistan. Sin profundidad, se darían únicamente cosas completamente desnudas, idénticas a sí mismas y, por así decirlo, impalpables con la mirada.

Lo que hay, pues, no son cosas idénticas a sí mismas que, posteriormente, se ofrecerían al vidente, y no es un vidente, vacío primero, que posteriormente se abriría a ellas, sino algo a lo que sólo podemos aproximarnos más palpándolo con la mirada, cosas que no podemos soñar con ver totalmente desnudas, porque la misma mirada las envuelve, las viste con su carne (Merleau-Ponty, 2010, pp. 119-120).

El sujeto vidente no es un contenedor vacío listo para ser llenado por el material sensible, sino que es instalado en el corazón de lo visible, envuelto en su tejido y destinado a hacerse él mismo visible desde otro lugar: "yo estoy en el corazón de lo visible y estoy lejos de él: [...] y por ende destinado a ser visto por un cuerpo" (Merleau-Ponty, 2010, p. 123). Esta ambigüedad estructural, que nos permite ver de cerca y, al mismo tiempo, nos hace visibles desde lejos, 
y que nos ubica simultáneamente aqui-ahora y allá-después, constituye una dimensión de coincidencia no reversible entre mi perspectiva y la del otro. La caracterización de esta paradójica estructura de la subjetividad, en cuanto ser en-el-mundo y al mismo tiempo ser al-mundo, lleva a Merleau-Ponty (2010) al descubrimiento de "ese Ser que está entre mi perspectiva y la de otro, entre mi pasado y mi presente" (p. 194); ser que Merleau-Ponty llama ser de latencia, en-être o carne. En otros términos, se trata del descubrimiento del ser como en-être, es decir, como profundidad o espesor de carne entre el vidente y la cosa vista. "Es que la consistencia de la carne entre el vidente y la cosa es constitutiva de la visibilidad de ella y de la corporeidad de él; no es un obstáculo entre ambos, es su medio de comunicación" (Merleau-Ponty, 2010, p. 123). Dicho de otra forma, las cosas no se dan a mi experiencia no obstante su profundidad o no obstante la mitad que queda encubierta, "sino gracias a esta, porque, si yo pudiera tener acceso directo a todos los aspectos [de una estatua] en el mismo instante, la estatua dejaría automáticamente de ser lo que es para volverse algo distinto" (Seggiaro, 2009, p. 51).

\section{La casi-reversibilidad del otro}

Se mencionó hasta ahora la ambigüedad y la bidimensionalidad de la donación en carne que nos remite a la concepción de un ser en cuanto en-être, que contiene su negación y que se interpone entre $m i$ perspectiva y la del otro, y que excluye la concepción de un ser como algo inmóvil e idéntico a sí mismo $0^{6}$ "la carne del mundo es Ser-visto [...] no el Ser-en-sí, idéntico a sí mismo, en la noche, sino el Ser que contiene también su negación, su percipi" (Merleau-Ponty, 2010, p. 221). En la topología del ên-etre, el ser mismo se presenta como aquel espectáculo del que el sujeto espectador hace parte. Ninguna visión de sobrevuelo o externa al espectáculo es ahora admisible, porque "es el sujeto percipiente mismo el que goza de la visibilidad del ser y porque el sujeto a su vez hace referencia al espectáculo de la visión” (Kirchmayr, 2008,

6 Sobre la relación entre en-être, carne y reversibilidad remitimos a Ballabio (2016, pp. 272-280). 
p. 213). El en-être se expresa, entonces, como relación con la situación finita de un sujeto envuelto en el mundo y que percibe el mundo, es decir, remite a la condición de un sujeto que está en el mundo, si bien constituyéndolo. En este sentido, "el uno y el otro, el sujeto y el ser, deben concebirse juntos, como el anverso y el reverso de una misma superficie plástica” (Kirchmayr, 2008, pp. 211-212). En otros términos, l'en-être se determina como un ser de relación, o como aquella superficie plástica en que el sujeto y el ser, el cuerpo y el mundo, se entrecruzan y se envuelven indisolublemente. Del mismo modo, la carne se configura como el lugar de encuentro de estas relaciones quiasmáticas: "un enredo paradójico que no es oportuno deshacer, pero del cual se deben reconocer los nudos particulares" (Kirchmayr, 2008, p. 212). La carne no es, entonces, un hecho entre otros hechos o una constelación de hechos positivos, sino aquel enredo paradójico a partir del cual cada hecho se individúa, es decir, se inscribe como tal en su verdad: "el mundo, la carne no como hecho o suma de hechos, sino como lugar de una inscripción de verdad: lo falso tachado, no anulado" (Merleau-Ponty, 2010, p. 120, n. 65).

En la topología plástica del en-être o de la carne, la oposición entre sujeto y ser, entre consciencia y mundo, decae en favor de un envolvimiento recíproco, en el que los dos términos de la relación "no se confunden entre ellos, sino que conservan sus propias peculiaridades" (Seggiaro, 2009, p. 49). En la donación en carne, el sujeto y el ser, el yo y el otro, no se dan como términos positivos de la relación, sino como dos atrios o aperturas. "En realidad no hay yo ni otro como positivos, subjetividades positivas. Son dos otros, dos aperturas, dos escenarios donde va a suceder algo - y ambos pertenecen al mismo mundo, al escenario del Ser" (Merleau-Ponty, 2010, p. 232). En este sentido, interior y exterior pertenecen al mismo horizonte de sentido y no son otra cosa que los dos lados costituyentes de la misma superficie fronteriza.

La idea de un punto de inversión, de un punto de pliegue que conecta los dos lados de un mismo tejido de mundo, nos remite a la noción merleaupontiana de reversibilidad, es decir, de composibilidad entre sujeto y ser, entre yo y otro y viceversa. En una nota de trabajo del 16 de noviembre de 1960, Merleau-Ponty nos explica el concepto de reversibilidad mediante la imagen del guante al que se ha dado la vuelta. 
Reversibilidad: el dedo del guante que se da vuelta. No es necesario un espectador que se sitúe en ambos lados. Basta con que, de un lado, yo vea el reverso del guante que se aplica sobre el anverso, con que toque uno por el otro (doble 'representación' de un punto o plano del campo) el quiasmo es eso: la reversibilidad (Merleau-Ponty, 2010, p. 232).

Según el filósofo francés, para hacer experiencia de la extremidad del dedo del guante volteado, no debemos convertirnos en espectadores de las dos partes del guante, el anverso y el reverso, sino que es suficiente tocar la una con la otra. Del mismo modo, podremos conocer la alteridad del otro estrechándole la mano y sin deber transponerle analógicamente nuestro ego:

si, al estrechar la mano de otro hombre, tengo la evidencia de que está aquí, es que ella sustituye mi mano izquierda, que mi cuerpo se anexiona el cuerpo de otro en esta "especie de reflexión" de la cual es, paradójicamente, la sede (Merleau-Ponty, 1964, p. 205).

Por ende, se podría afirmar que por sustitución tocamos el reverso por medio del anverso y que reconocemos al otro mediante nosotros mismos, y viceversa. A su vez, el otro no es un pretexto, sino una ocasión por la cual nos volvemos visibles y cognoscibles a nosotros mismos. En este sentido, las cosas y los otros forman un sistema de visiones que abre un escenario en el que la mirada del otro puede alcanzarnos y ver lo que para nosotros es invisible. Por ejemplo, el otro puede ver mi espalda o mi cabeza.

Así, cada objeto es el espejo de todos los demás y [...] cada uno de ellos dispone de los demás, que están a su alrededor, como espectadores de sus aspectos ocultos y garantía de su permanencia. Toda visión de un objeto por mí se reitera instantáneamente entre todos los objetos del mundo que son captados como coexistentes porque cada uno es todo lo que los demás "ven" de él (Merleau-Ponty, 1993, p. 88).

Dado que cada cosa se individúa a partir de lo que los otros ven de ella, somos todo lo que los otros ven de nosotros: nosotros que vemos, somos también vistos por los otros. Nuestra experiencia se rige por esta posibilidad de revolvimiento o reversibilidad que hay entre nosotros y el otro, y por la cual quizás “el sí mismo y el no-sí mismo sean como el reverso y el anverso, y acaso 
nuestra experiencia sea esa inversión que nos instala muy lejos de nosotros, en otra persona, en las cosas" (Merleau-Ponty, 2010, p. 146). En este sentido, cada identidad no es algo ya dado, sino un proceso vital que nace en la relación con las otras cosas y con los otros: "cada uno es todo lo que los demás 'ven' de él" (Merleau-Ponty, 1993, p. 88). Este desdoblamiento reversible, por el que cada término de la relación encuentra su propia identidad para el otro y a partir del otro, no establece un tipo de relación sujeto-objeto en una dirección única. En cambio, nos muestra un tipo de "relación reversible, en la que el uno y el otro polo se intercambian continuamente los roles, [...] es más, las polaridades literalmente no se dan antes de la relación misma" (Lisciani-Petrini, 1999, p. 171). Si la identidad envuelve la alteridad, esta última está a su vez envuelta en ella. No podemos admitir ninguna identidad preconcebida, pero tampoco una relación preestablecida que se da antes de sus partes, así como acota Simondon: "es la relación misma de la parte al todo la que se encuentra transformada [...]: ningún individuo puede ser concebido en ningún momento a salvo de la acción posible de otro individuo" (Simondon, 2009, p. 183). Lo que se da en original es el horizonte que asegura la identidad y la diversidad entre los polos de la relación, pero este es una explosión que acontece y no una capa de sentido que precede a las diferencias o está debajo de ellas. Así, "la realidad se presenta en cuanto desenvolvimiento de relaciones, una propagación de reflejos: como la explosión instantánea de un espacio topológico" (Lisciani-Petrini, 1999, p. 172). Merleau-Ponty (2010) concibe la reversibilidad de los opuestos "como dos segmentos de un solo recorrido circular, que, por arriba, va de izquierda a derecha, y por abajo, de derecha a izquierda, pero que no es más que un único movimiento en sus dos fases" (p. 125). O lo que es mejor: "si debemos renunciar una vez más al pensamiento por planos y perspectivas, hay dos círculos, o dos torbellinos, o dos esferas, concéntricas cuando yo vivo ingenuamente $y$, cuando me interrogo, débilmente descentradas una respecto de la otra...” (Merleau-Ponty, 2010, p. 126). Los polos de la relación serían dos torbellinos concéntricos, débilmente descentrados el uno respecto del otro por nuestra libre reflexión. Somos visibles desde el punto de vista de otro, y este es visible desde nuestro punto de vista: ambos somos visibles porque estamos inscritos en la visibilidad. El filósofo francés diría que somos moradas 
abiertas el uno para el otro, y viceversa. Hay reversibilidad, pero se trata de una casi-reversibilidad, siempre inminente, pero nunca realizada de hecho.

Mi mano izquierda está siempre a punto de tocar a mi mano derecha tocando las cosas, pero nunca logro la coincidencia; ésta se eclipsa en el momento de producirse, y siempre se da una de dos: o mi mano derecha pasa realmente a la condición de tocada, pero entonces se interrumpe su captación del mundo, o bien ella la conserva, pero entonces yo no la toco realmente a ella, sólo palpo con mi mano izquierda su envoltorio exterior (Merleau-Ponty, 2010, p. 133).

El fenómeno de la reversibilidad no es nunca completamente transparente a sí mismo, sino que es un movimiento bidireccional cuyas fases implican continuos retardos. Como hemos descrito precedentemente, se trata de un fenómeno caracterizado por un residuo esencial entre los extremos de la relación, la cual no es perfectamente simétrica y coincidente, sino descentrada y oblicua. De hecho, entre el cuerpo vidente y visto y entre la mano tocante y tocada hay siempre un residuo y un retraso de impercepción, que impide una reversibilidad completa: los dos polos se revelan paradójicamente y últimamente irreversibles. Si el proceso cognoscitivo implica el fenómeno de la reversibilidad, este, a su vez, implica la permanencia de un residuo de incognoscibilidad. Apenas me interrogo e intento una reflexión sobre la experiencia, descubro aquel descentramiento constitutivo entre la mano tocante y la mano tocada, entre mi mano y la del otro y, definitivamente, entre yo y el otro. "Ninguna reflexión podrá traer dentro de sí el por qué esto acontece, y el por qué este entramado existe. Este es el fondo de no reflexión que nunca puede ser llevado dentro del cono de luz de la reflexión" (Lisciani-Petrini, 1999, p. 177). Nuestro conocimiento se caracteriza por un fondo de no reflexión, que nunca se puede tematizar, que es el responsable del retardo estructural de nuestro conocimiento.

Por esto, lo que agarramos es siempre y solamente el espectáculo del mundo, de las relaciones en acto, pero nunca aquella apertura de mundo, aquella instantánea explosión, que es ya y desde siempre aquí, de hecho sin nunca serlo, y que se nos escapará en el momento en que el esfuerzo reflexivo busque captarla. Con respeto a ella, entonces, el pensamiento no puede más que llegar siempre en retraso (Lisciani-Petrini, 1999, p. 177). 
Podemos afirmar con Merleau-Ponty que hay un hiato esencial, y no accidental, entre nuestra percepción y la cosa percibida, entre nuestro pensamiento y la explosión instantánea del objeto, "por la razón de que yo veo hoy una estrella quizás apagada desde hace años, y que en general toda percepción atrasa respecto de su objeto" (Merleau-Ponty, 2010, p. 143). En todo caso, este retraso constitutivo entre la percepción y el mundo y entre nosotros y el otro, lejos de ser un obstáculo para el conocimiento, es la única y esencial condición de posibilidad para la experiencia de los otros y de las cosas en cuanto individuos.

\section{La alteración del individuo}

Hasta ahora pudimos constatar cómo el objeto del conocimiento se presenta siempre como una alteridad: los otros o las otras cosas. Además, hemos aclarado cómo nosotros, lejos de ser sujetos de sobrevuelo que observan desinteresados desde lo alto, llegamos siempre en retraso al encuentro con la alteridad. La alteridad es tal en tanto ya ha pasado o debe aún venir, y en cada caso huye y excede nuestro presente. Pero precisamente la experiencia de esta diferencia o excedencia que no se puede colmar con respeto al otro nos abre a la posibilidad de conocerlo. "Es necesario entonces que la distancia, sin la cual la experiencia de la cosa o del pasado se reduciría a cero, sea también apertura a la cosa, al pasado, que entre en su definición" (Merleau-Ponty, 2010, p. 114). Lo que se nos ha dado en el encuentro con la alteridad no es, entonces, una cosa desnuda o un pasado, así como era, "sino la cosa dispuesta a ser vista, cargada, tanto por principio como de hecho, de todas las visiones que de ella pueden tomarse: el pasado tal como fue un día, más una inexplicable alteración, una extraña distancia” (Merleau-Ponty, 2010, p. 114). La presencia del otro implica por ende una alteración de nuestra esfera de propiedad, porque desquicia nuestro aquí y ahora en el mundo y nos proyecta afuera de nosotros. Del mismo modo, si el objeto de conocimiento no es una cosa desnuda, sino algo listo para ser visto desde otras visiones composibles a la nuestra, no está cerrado en sí mismo, sino abierto al otro. En otras palabras, el objeto está 
siempre sujeto a posibles alteraciones que lo proyectan afuera de sí: no es estático, sino ek-stático.

Entonces, sujeto y objeto están proyectados afuera de sí, disponibles al encuentro con el otro. En este sentido, "el hombre puede hacer el alter ego que no puede hacer el 'pensamiento', porque se encuentra fuera de sí en el mundo y porqué un ek-stasis es susceptible de entrar en composición con otros" (Merleau-Ponty, 1964, p. 209). Pero ¿qué tenemos en común nosotros y los otros? En el encuentro con el otro, en el intercambio de un apretón de manos "hago experiencia de una común intercorporeidad mediante la cual estoy originariamente entrecruzado con los otros en una misma trama carnal' (Kirchmayr, 2008, p. 208). Así, el otro "aparece por extensión de esta copresencia, él y yo somos como los órganos de una única intercorporeidad" (Merleau-Ponty, 1964, p. 205). Tanto mi cuerpo como el ajeno se individúan en virtud de una intercorporeidad común, es decir, de un mismo entramado carnal, que Merleau-Ponty identifica con el concepto de elemento, procedente de la filosofía jónica: "la carne no es materia, no es espíritu, no es substancia. Sería necesario, para designarla, el viejo término de 'elemento'" (Merleau-Ponty, 2010, p. 127). En otros términos, aquel elemento general y común por el cual el yo y el otro, "pasado y presente son Ineinander, cada uno envuelto-envolvente [...] es la carne" (Merleau-Ponty, 2010, p. 236). Entonces, es válido un principio de sustitución: tanto mi aquí, mi cuerpo, como el aquí del otro, su cuerpo, se individúan en virtud de su común intercambiabilidad, que no es más que el poder que cada individuo tiene de salirse de sí y volver en sí. "La constitución de lo otro no viene después de la del cuerpo, lo otro y mi cuerpo nacen juntos del éxtasis original” (Merleau-Ponty, 1964, p. 212). Raoul Kirchmayr (2008) subraya justamente que "el principio de sustitución aquí procede paralelamente al principium individuationis” (p. 210), en un sentido que ahora debemos intentar comprender.

Hasta ahora, el concepto de reversibilidad nos ha llevado a pensar en los polos de la relación yo-otro, como el anverso y el reverso de un mismo elemento, al mismo tiempo envueltos y envolventes. La identidad y la alteridad, mi cuerpo y el ajeno se determinan el uno como la milagrosa prolongación del otro, y viceversa. Incluso, "no hay un único cuerpo anónimo y operativo, antecedente a la individuación, de la cual los cuerpos singulares serían el an- 
verso y el reverso" (Kirchmayr, 2008, p. 210). Si seguimos el razonamiento de Merleau-Ponty, podemos admitir con él que "no hay identidad, ni no-identidad o no-coincidencia, hay adentro y afuera girando uno en torno al otro. Mi nada 'central' es como la punta del espiral estroboscópico, que está no se sabe dónde, que es 'nadie"' (Merleau-Ponty, 2010, p. 232). Hay una intercorporeidad preindividual anónima y operativa, anterior a cada individuo y que es “'nadie', en el sentido de Ulises, como el anónimo que huye al mundo y que todavía no ha dejado en él su huella” (Merleau-Ponty, 2010, p. 179). Podemos comparar este elemento anónimo y preindividual con el imperceptible fondo de irreflexión ya mencionado y contraseñado por una evidencia de desposesión e incognoscibilidad: "es justamente porque se sabe demasiado bien de qué se trata que no se necesita plantearlo en ob-jectum. Anonimato y generalidad" (Merleau-Ponty, 2010, p. 179). El yo y el otro están entrelazados por un anónimo y desconocido espesor de realidad que envuelven y por el cual están envueltos, y que es anterior a cada proceso de objetivación e individuación. Entre mi yo y el del otro no se presenta nada más que una laguna o una cavidad de ser, que no es un hueco, sino una zona intermedia que permite el pasaje desde el anonimato preindividual al individuo.

Ahora bien, cabe preguntarnos: ¿cómo se configura el proceso de individuación en Merleau-Ponty? ¿Qué tipo de relación hay entre individuo y generalidad anónima o preindividualidad? ¿Qué concepto de individuación está implicado en el ser como quiasma y reversibilidad? ¿Cómo se debe entender la noción de preindividual en Merleau-Ponty? En Lo invisible y lo visible (2010), Merleau-Ponty esboza su concepción fundamental de individuo con estas palabras:

Nunca tenemos ante nosotros individuos puros, glaciares de entes indivisibles, $\mathrm{ni}$ esencias sin lugar y sin fecha, no porque existan en otro lugar, fuera de nuestro alcance, sino porque somos experiencias, es decir pensamientos, que experimentan tras de sí el peso del espacio y del tiempo, del Ser mismo que estos piensan, que por lo tanto no mantienen bajo su mirada un espacio y un tiempo serial ni la pura idea de las series, sino que tienen a su alrededor un tiempo y un espacio de apilamiento, de proliferación, de intrusión, de promiscuidad — perpetua preñez, perpetuo alumbramiento, generatividad y generalidad, esencia bruta y existencia bruta, que son los vientres y nodos de la misma vibración ontológica- (p. 107). 
En este sentido, los individuos no son, por así decirlo, seres puros o cosas desnudas más allá o arriba del tiempo y del espacio, sino seres sujetados a la presión del tiempo y del espacio. Ellos padecen la actividad, y del mismo modo habitan el tejido espacio-temporal no exacto, sino tosco y fecundo, del cual son los vientres y nudos vibrantes. La filosofía debe, entonces, mostrarnos cómo este fondo de irreflexión, este tejido bruto y general de carne, no es nada, sino algo que permite la aparición del individuo: "la filosofía como interrogación [...] sólo puede consistir en mostrar cómo el mundo se articula a partir de un cero de ser que no es una nada" (Merleau-Ponty, 2010, p. 229).

Con el propósito de observar la génesis del individuo desde un estrado anónimo y preindividual, resulta fructífero acercarnos al concepto de individuación elaborado por Gilbert Simondon (2009), discípulo de Merleau-Ponty:

La individuación debe ser captada como devenir del ser, y no como modelo del ser que agotaría su significación. El ser individuado no es todo el ser ni el ser primero; en lugar de captar la individuación a partir del ser individuado, es preciso captar el ser individuado a partir de la individuación, y la individuación, a partir del ser preindividual (p. 37).

Paolo Gambazzi (1999) acota que Simondon piensa la individuación, es decir, la constitución del individuo en cuanto tal, como "una modulación de un tema, y no la copia realizada (en la realidad) de un modelo" (p. 254). De la misma forma, Vargas (2014) observa que individuarse es diferenciarse:

Se individúa lo ente; se diferencia con respecto a lo ente. Aquél toma las propiedades propiamente propias como su interioridad y se limita a sí mismo, crea un límite desde sí. Desde luego, comienza teniendo límites o bordes borrosos. Dentro de lo común se desfasa, desde sí, haciéndose referente de sí: centro descentrado con respecto a lo mismo de lo que es parte; constituyéndose como otro, lo otro, con respecto a esto mismo (p. 25).

En su texto inédito, Histoire de la notion d'individu (2005), Simondon afirma que "el principio de individuación, si no es exterior, por lo menos es anterior al individuo; él se prolonga en el individuo bajo la forma de un dinamismo de crecimiento" (p. 47). Pensar al individuo como la determinación de una forma, con base en un modelo preestablecido, excluye la idea simon- 
doniana de la individuación en cuanto modulación constantemente variable. Merleau-Ponty, en una nota de trabajo inédita, de 1959, menciona explícitamente a Simondon y conviene con su concepción de individuación como proceso vital en constante evolución: "bajo el punto de vista de una biología moderna, por el contrario, hay la idea (Simondon p. 231) de una herencia como prolongación de la ontogénesis, de la individuación, estas últimas entendidas como procesos vitales" (Merleau-Ponty, 1959, p. 39). Modulación, dinamismo y proceso vital son, entonces, los títulos de la individuación simondoniana, que remiten a la idea merleaupontiana de un pasaje/tránsito reversible del fondo preindividual y anónimo al individuo concreto. Un pasaje del cual el individuo conserva la huella, y que se configura como la condición instituyente de los individuos. Al respecto, Emmanuel De Saint Aubert (2005), introduciendo dos textos inéditos sobre la individuación de Merleau-Ponty y Simondon, escribe que

el pasaje se hizo, hay pasaje, o mejor hubo pasaje. Lo cual significa que nosotros somos siempre antes o después, que no asistimos a él. Lo individual es irrecusable y, por lo tanto, como un cristal su propia agua-madre, lleva siempre en sí lo preindividual, como rasgo de lo que lo ha precedido y germen de lo que lo superará (p. 28).

Para comprender la individuación simondoniana, es oportuno pensar al individuo como proceso en la totalidad de su darse, es decir, como fases de un devenir que conserva el rasgo de la dimensión preindividual:

el ser preindividual es el ser en el cual no existe fase; [... La individuación corresponde a la aparición de fases en el ser que son las fases del ser [...]; se podría decir en un cierto sentido que el único principio por el que uno puede guiarse es el de la conservación del ser a través del devenir (Simondon, 2009, p. 27).

En este sentido, para Simondon resulta inconcebible un individuo abstraído de su propio dinamismo de concreción en el ambiente; más aún, el individuo es precisamente el proceso de ambientación concreta de lo preindividual. "El individuo no es el único aspecto del ser; él es todo el ser sólo/solamente con el complemento que es el ambiente, generado al mismo tiempo que el 
individuo" (Simondon, 1989, p. 142). El ser completo, el ensemble absolu, es la totalidad del proceso vital que desemboca en la concreción del individuo en su ambiente; es anterior a la individuación y se ubica "al límite entre el individuo y lo que queda de él, según una mediación suspendida entre la trascendencia y la inmanencia" (Simondon, 1989, p. 137). L'ensemble absolu se sitúa, entonces, en aquella zona intermedia entre el individuo y su ambiente, sin invadirlos y dejándolos modularse y concretarse libremente. L'ensemble absolu simondoniano nos remite al concepto de carne o de en-être merleaupontiano, como algo que no se encuentra sobre o debajo de los individuos, sino que está entre ellos, en aquellas junturas del ser en las que el individuo es "el otro diferente del otro, y la identidad diferencia de diferencia" (Merleau-Ponty, 2010, p. 233).

El proceso de individuación, entendido como pasaje desde lo preindividual al individuo, no se caracteriza como un proceso de encarnación empírica de una esencia ya dada y preconstituida en otro lugar y que se concretaría aquí y ahora.

No hay aquí un problema de alter ego, porque no soy yo quien ve, no es él quien ve, sino que una visibilidad anónima nos habita a ambos, una visión en general, en virtud de esa propiedad primordial perteneciente a la carne de irradiar a todas partes y para siempre estando aquí y ahora, de ser también dimensión y universal siendo individuo (Merleau-Ponty, 2010, p. 129).

En su ser "universalidad siendo individuo", la carne se configura como aquel horizonte ambivalente y trascendental que asegura la reversibilidad en cuanto principium individuationis, o "doble referencia, la identidad del entrar en sí y salir de sí, de la vivencia y de la distancia” (Merleau-Ponty, 2010, p. 114). La individuación no es, entonces, un mero proceso de conocimiento del otro, sino de conocimiento con el otro. Se trata de un movimiento en dos direcciones en el que el sujeto se individúa saliendo de sí, es decir, alterándose, y retrotrayendo en sí la diferencia con el otro, su estilo peculiar o, si se prefiere, el buen error que es el otro. 


\section{REFERENCIAS}

Ballabio, A. (2016). Experiencia y creatividad en C. S. Peirce y M. Merleau-Ponty. Bogotá: Aula de Humanidades.

Barbaras, R. (1998). Le tournant de l'expérience. Recherches sur la philosophie de Merleau-Ponty. Paris : Vrin.

De Carlo, S. (2012). L'inflessione dello sguardo. L'ontologia indiretta di Maurice Merleau-Ponty attraverso l'interrogazione sulla natura. Genova: Il Melangolo.

De Saint Aubert, E. (2005). De l'Être brut à l'homme. Contextualisation de deux notes inédites de Merleau-Ponty. Chiasmi International, 7, 25-28.

Gambazzi, P. (1999). Fissione dell'essere, essenze e visibilità assoluta. Individuazione e ecceità della cosa nell'ultimo Merleau-Ponty. Chiasmi International, 1, 253-271.

Kirchmayr, R. (2008). Merleau-Ponty: Una sintesi. Milano: Marinotti Edizioni.

Lisciani-Petrini, E. (1999). Attivitá/passivitá: L'invisibile di Merleau-Ponty. Chiasmi International, 1, 169-183.

Merleau-Ponty, M. (1959). Notes de travail inédites (Bibliothéque Nationale de France, Vol. VIII). Chiasmi International, 7, 39-42.

Merleau-Ponty, M. (1964). Signos. Barcelona: Seix Barral.

Merleau-Ponty, M. (1993). Fenomenología de la percepción. Barcelona: Planeta-De Agostini.

Merleau-Ponty, M. (1995). La nature. Notes. Cours du Collège de France. Paris: Seuil.

Merleau-Ponty, M. (2010). Lo visible y lo invisible. Buenos Aires: Nueva Visión. 
Prandoni, A. (2000). Il sensibile dimensionale: Essenza grezza e reversibilità istituente nella riflessione ontologica merleau-pontiana. Chiasmi International, 2, 451470 .

Seggiaro, N. (2009). La chair et le pli: Merleau-Ponty, Deleuze e la multivocità dell'essere. Milano: Mimesis.

Simondon, G. (2005). Histoire de la notion d'individu. Chiasmi International, 7 , 45-54.

Simondon, G. (2009). La individuación. A la luz de las nociones de forma e información. Buenos Aires: La Cebra-Cactus.

Vargas Guillén, G. (2014). Individuación y anarquia: metafisica y fenomenología de la individuación. Bogotá: Aula de Humanidades-Universidad San Buenaventura. 